OxCal v4.0 Bronk Ramsey (2006);

r:5; IntCal04 atmospheric curve (Reimer et al 2004)

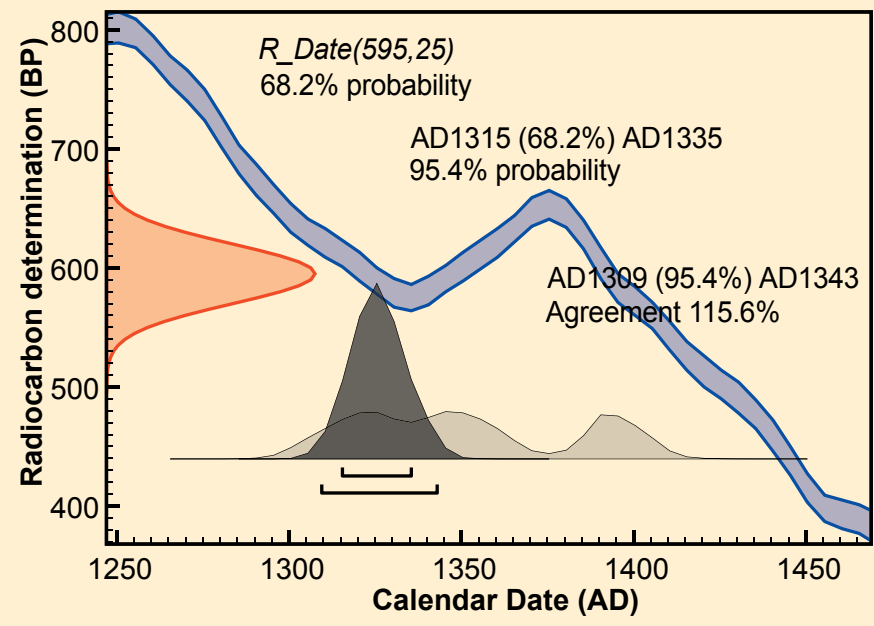

Figure 2: A typical radiocarbon calibration probability distribution (light grey) based on the radiocarbon determination represented by the normal distribution (left axis; red). The result of the overall age model on this particular sample is shown in dark grey. Such resultant probability distributions can be generated for any point in the deposition model (including levels not directly dated).

els is that you get a realistic assessment of the uncertainty of age at any depth. This is important if deciding whether changes or events recorded in a sequence are really synchronous with those in other similarly modeled sequences.

\section{Integrating temporal information into one model}

Although generating age-depth models with properly estimated uncertainties is certainly an advance, in many ways the real power of this approach is the ability to integrate information from several different records together. If we have truly synchronous markers, such as tephra, present in the records, then this information can be incorporated into an overall model giving better chronological resolution and, more critically, good relative date information between the records in question-even at some distance from the tie points. In other cases, the tie points might link the chronology to that of the ice cores and allow comparison of climatic information from very different locations.

The other positive aspect of a numerical model of this kind is that it can easily be used to generate other information of interest, for example, the age difference between two events, or the deposition rate for a segment of a particular record. The information obtained in this way is also given in the form of a probability distribution function, with properly assessed uncertainties.

\section{Conclusions and prospects}

The questions that need to be addressed in the study of past changes in the Earth require a chronological resolution that pushes our dating techniques to their limit. In this context, we can no longer generate age models by simply drawing straight lines through our data; we need to estimate the uncertainties in our age models and we need to allow for the kinds of natural fluctuations that take place in deposition.

The suite of models now available in OxCal (Bronk Ramsey, 2007), and in other analysis packages such as BPeat (Blaauw and Christen, 2005) allow us to start to address these issues in a comprehensive way. In some cases, such an approach may simply tell us that the information we have is not sufficient to answer some of the key questions. However, in other cases, the ability to integrate information from so many different sources may allow us to see patterns and processes in action that had previously been obscure.

\section{Note}

More information on the methods discussed in the article, including links to the program are given on:

http://c14.arch.ox.ac.uk/oxcal.html

\section{References}

Blaauw, M. and Christen, J.A., 2005: Radiocarbon peat chronologies and environmental change, Journal of the Royal Statistical Society Series C-Applied Statistics, 54: 805-816.

Bronk Ramsey, C., 1995: Radiocarbon calibration and analysis of stratigraphy: The OxCal program, Radiocarbon, 37: 425-430.

Bronk Ramsey, C., Deposition Models for Chronological Records: Quaternary Science Reviews, INTIMATE special issue, in press.

Buck, C.E., Christen, J.A. and James, G.N., 1999: BCal: an on-line Bayesian radiocarbon calibration tool, Internet Archaeology, 7: http://intarch. ac.uk/journal/issue7/buck_index.html.

Buck, C.E. and Millard, A., 2004: Tools for constructing chronologies: crossing disciplinary boundaries, Springer, London, xix: 257 pp.

Jones, M. and Nicholls, G., 2002: New radiocarbon calibration software, Radiocarbon, 44: 663-674.

\title{
21 st century suck-in or smear: Testing the timing of events between archives
}

\author{
M. Blaauw ${ }^{1}$, J. Andrés Christen ${ }^{2}$, D. Mauquoy ${ }^{3}$, J. van der Plicht ${ }^{4}$, K. D. Bennett ${ }^{1}$ \\ 'Palaeobiology, Uppsala University, Sweden; maarten.blaauw@geo.uu.se \\ ${ }^{2}$ Centro de Investigación en Matemáticas, Guanajuato, Mexico \\ 32Department of Geography and Environment, University of Aberdeen, UK \\ ${ }^{4}$ Centre for Isotope Research, University of Groningen, and Faculty of Archaeology, Leiden University, The Netherlands
}

\section{Introduction}

Proxy-archives are frequently compared with other data in order to imply teleconnections between regions. Well-known examples of widely recorded past climate events are the last glacial-interglacial transition, the " 8.2 kyr event", and the "Little Ice Age". Although we do not question the existence of these events, reported synchronicity between archives could have been caused by age-modeling errors, mistaken interpretations of proxy data, or even by "wishful-thinking".
Archives could have been tuned to other archives, age-models selected subjectively, non-responsive sites neglected, or suggestive lines drawn connecting events between archives. It is this potentially dangerous practice of sucking-in or smearing of events (cf. Baillie, 1991; Wunsch, 2006) that we will discuss here. We apply recently developed methods (Blaauw et al., in press) to test the timing of events between two well-dated archives.

\section{Common approaches}

Let's start with a short review of the usual steps to date and compare non-annual archives:

1) Single archives are dated by, for example, radiocarbon at several depths.

2) These dated levels, with their often considerable chronological uncertainties, are reduced to point estimates (e.g. the midpoints of the calibrated ranges for ${ }^{14} \mathrm{C}$ dates).

3) A single curve is drawn through these points (e.g. linear interpolation, regres- 


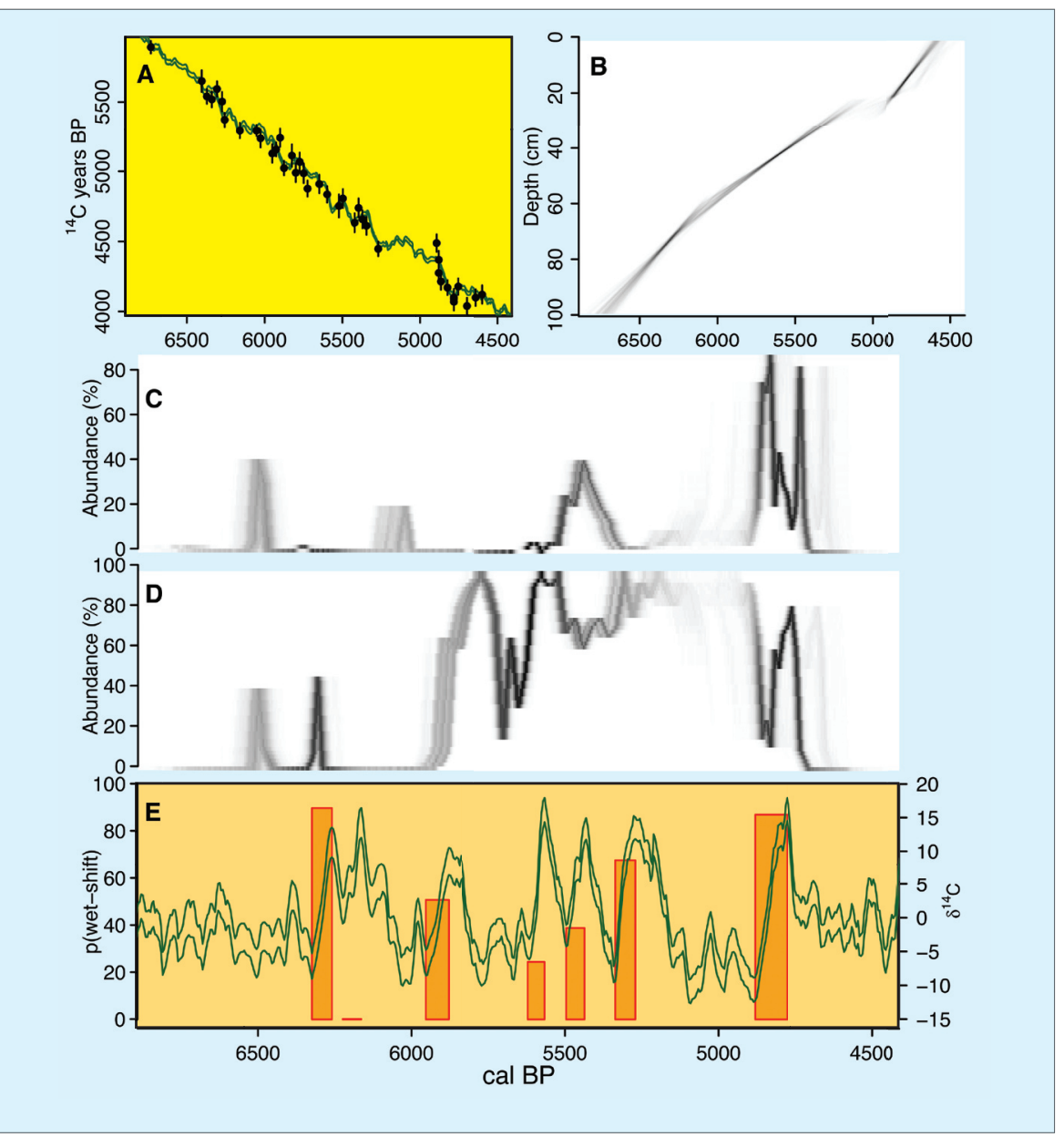

Figure 1: Age-modeling of core MSB-2K from a raised bog deposit in The Netherlands (Blaauw et al., 2004). A: Best fit of the ${ }^{14} \mathrm{C}$ dates to the IntCal04 calibration curve. $\boldsymbol{B}$ : millions of age-depth models indicate likely (dark) and more uncertain (light-grey) cal years for every depth of a core. $\boldsymbol{C}$ : The age-models from B are plotted, replacing the depths by the values of the proxy Sphagnum cuspidatum at those depths (Blaauw et al., in press). D: as C but for proxy Scheuchzeria palustris. $\boldsymbol{E}$ : Green lines show 1- $\sigma$ uncertainty envelope of $\triangle^{14} \mathrm{C}$ (measured to yearly precision using dendrochronology; right $y$-axis). Orange bars are placed during major rises of $\triangle^{14} C$, their heights showing the probability that a wet-shift took place in core MSB-2K during these time-windows (left y-axis).

sion), which then forms the age-model; this age-model entirely neglects the often considerable chronological uncertainties connected to both the dates and the modeling assumptions.

4) It is this single curve which is then used to convert every depth (either dated or non-dated) to a single calendar age, after which line diagrams are drawn to show the proxy values against calendar age. 5) These proxy diagrams are compared with other studies, in graphical comparisons where it is up to the reader to "eyeball" synchronous events (although authors often help their readers by connecting peaks between archives with lines; see also Wunsch, 2006).

\section{Age-model uncertainties}

We argue that the above process can easily lead to overly subjective comparisons, and that more systematic tests for synchronicity between archives are needed (Blaauw et al., in press). Firstly, we propose to step away from using just one curve to translate depths into calendar ages. Using Bayesian methods, it is possible to construct millions of likely age-models, including information such as that dates in a sequence are ordered chronologically, and that some accumulation rates are more likely than others (Blaauw and Christen, 2005). Each of these age-models will give a slightly different calendar age estimate to the depths of a sequence. For every depth, the likely calendar ages can be plotted as grey-scales, with darker colors indicating more likely calendar ages (Fig. 1). The same age-models can be used to plot proxy values against calendar age, again indicating more likely calendar ages by darker values and thereby visualizing the chronological uncertainty of proxy values (Blaauw et al., in press; Fig. 1). Dark areas indicate secure chronologies, while light grey areas warn us of insecure areas (e.g. around $5000 \mathrm{cal}$ BP in Fig. 1, at the time of a likely hiatus in the shown sequence).

\section{Testing for events}

Now let's take a closer look at Figure 1. The core was sampled from a Dutch raised bog deposit and dated at high resolution $\left(40{ }^{14} \mathrm{C}\right.$ dates over the 1 -m-long core; Blaauw et al., 2004). The grey-scale graphs in panels $C$ and $D$ show the chro- nologies (including uncertainties as explained above) of two wetness-indicating bog plant species; rising values are interpreted as changes towards wetter conditions. Using the eye-balling approach, it is interesting to note that many wet-shifts apparently correspond with sharp rises in $\Delta^{14} \mathrm{C}$ (indicating decreases in solar activity; panel E), for example around 6300, $5900,5500,5300$ and 4800 cal BP. However, using the previously mentioned millions of likely age-models, we can calculate the actual probability that these wet-shifts occurred during periods of rising $\Delta^{14} \mathrm{C}$ levels. We do this by choosing a time-window, for example 4880-4775 cal $\mathrm{BP}$ that corresponds to a large rise in $\Delta^{14} \mathrm{C}$, and then calculating which proportion of the millions of age-models assigns an age within this time window to those depths where wet-shifts were found (Blaauw et al., in press). The heights of the orange bars in the lowest panel of Figure 1 show the probabilities that wet-shifts took place during rising $\Delta^{14} \mathrm{C}$ levels. Some of these probabilities are reassuringly high (close to $100 \%$ ) but others linger around $20-40 \%$, which clearly is less convincing.

\section{Conclusion}

We think that incorporating chronological uncertainties in analysis of proxy data forms one step towards more systematic and less subjective use of proxy data. Here, the above methods have been applied to ${ }^{14} \mathrm{C}$-dated peat deposits, but the approach could be adapted to many other types of Quaternary environmental change archives. Hopefully, the agedepth modeling research outlined above will eventually enable us to find out which types of questions can, and which cannot, be confidently answered using proxy data. This is currently one of the biggest obstacles in Quaternary environmental change research.

\section{References}

Baillie, M.G.L., 1991: Suck in and smear: two related chronological problems for the 90s. Journal of Theoretical Archaeology, 2: 12-16.

Blaauw, M., van Geel, B. and van der Plicht, J., 2004: Solar forcing of climate change during the mid-Holocene: indications from raised bogs in The Netherlands. The Holocene, 14: 35-44.

Blaauw, M. and Christen, J.A., 2005: Radiocarbon peat chronologies and environmental change. Applied Statistics, 54: 805-816.

Blaauw, M., Christen, J.A., Mauquoy, D., van der Plicht, J. and Bennett, K.D. Testing the timing of radiocarbon-dated events between proxy archives. The Holocene, in press.

Wunsch, C., 2006: Abrupt climate change: an alternative view. Quaternary Research, 65: 191-203. 